\title{
Functional assessment of liver regeneration after major hepatectomy
}

\author{
Fadi Rassam $^{1}$, Pim B. Olthof ${ }^{1}$, Bart Takkenberg ${ }^{2}$, Marc G. Besselink ${ }^{1}$, Olivier R. Busch ${ }^{1}$, \\ Joris I. Erdmann ${ }^{1}$, Rutger-Jan Swijnenburg ${ }^{1}$, Krijn P. van Lienden ${ }^{3}$, Ulrich H. Beuers ${ }^{2}$, Roelof J. Bennink ${ }^{3}$, \\ Thomas M. van Gulik ${ }^{1}$
}

${ }^{1}$ Department of Surgery, Cancer Center Amsterdam, Amsterdam UMC, University of Amsterdam, The Netherlands; ${ }^{2}$ Department of Gastroenterology \& Hepatology, Amsterdam UMC, University of Amsterdam, Amsterdam, The Netherlands; ${ }^{3}$ Departments of Radiology and Nuclear Medicine, Cancer Center Amsterdam, Amsterdam UMC, University of Amsterdam, Amsterdam, The Netherlands

Contributions: (I) Conception and design: F Rassam, PB Olthof, B Takkenberg, MG Besselink, OR Busch, UH Beuers, RJ Bennink, TM van Gulik; (II) Administrative support: F Rassam, PB Olthof; (III) Provision of study materials or patients: MG Besselink, OR Busch, JI Erdmann, RJ Swijnenburg, TM van Gulik; (IV) Collection and assembly of data: F Rassam, PB Olthof, KP van Lienden, RJ Bennink; (V) Data analysis and interpretation: F Rassam, PB Olthof, B Takkenberg, KP van Lienden, UH Beuers, RJ Bennink; (VI) Manuscript writing: All authors; (VII) Final approval of manuscript: All authors.

Correspondence to: Fadi Rassam. Department of Surgery, Cancer Center Amsterdam, Amsterdam UMC, University of Amsterdam. Meibergdreef 9, 1105 AZ, Amsterdam, The Netherlands. Email: f.rassam@amsterdamumc.nl.

Background: Liver regeneration is crucial to restore the functional liver mass after liver resection. The aim of this study was to evaluate the early postoperative changes in remnant liver function, volume and liver stiffness after major liver resection and their correlation with postoperative outcomes.

Methods: Patients undergoing major liver resection ( $\geq 3$ segments) between February and November 2018 underwent both functional assessment using technetium-99m mebrofenin hepatobiliary scintigraphy (HBS) and CT-volumetry of the (future) remnant liver on preoperative day 1 , the $5^{\text {th }}$ postoperative day, and 4-6 weeks after resection. At the same time points, patients underwent transient elastography (TE) for the assessment of liver stiffness. Severe postoperative complications (Clavien-Dindo $\geq 3 \mathrm{~A}$ ) and mortality were correlated with the functional and volumetric increases of the remnant liver. Liver failure was graded according to the International Study Group of Liver Surgery (ISGLS) criteria.

Results: A total of 18 patients were included of whom 10 (56\%) had severe complications and one patient $(5 \%)$ developed liver failure. Function and volume of the remnant liver had increased by the $5^{\text {th }}$ postoperative day from $6.9(5.4-10.9)$ to $9.6(6.7-13.8) \% / \mathrm{min} / \mathrm{m}^{2}, \mathrm{P}=0.004$ and from $795.5(538.3-1,037.5)$ to $1,080.0$ (854.0-1,283.3) $\mathrm{mL}, \mathrm{P}<0.001$, respectively. After 4-6 weeks, remnant liver volume had further increased [from 1,080.0 (854.0-1,283.3) to 1,222.0 (1,016.0-1,380.5) $\mathrm{mL}, \mathrm{P}=0.035$ ], however, liver function did not show any significant, further increase [from $9.6(6.7-13.8)$ to $10.9(8.8-13.6) \% / \mathrm{min} / \mathrm{m}^{2}, \mathrm{P}=0.177$ ]. Liver elasticity of the future remnant liver (FRL) increased [from $10.8(5.7-18.7)$ to 17.5 (12.4-22.6) $\mathrm{kPa}, \mathrm{P}=0.018$ ] and gradually recovered after 4-6 weeks to a median of 10.9 (5.7-18.8) $\mathrm{kPa}$ (T3 vs. T4, P=0.079). Patients who had severe postoperative complications did not show a significant increase in liver function on the $5^{\text {th }}$ postoperative day $(\mathrm{P}=0.203)$, despite increase of volume $(\mathrm{P}<0.01)$.

Conclusions: Functional regeneration of the remnant liver predominantly occurs during the first 5 days after resection. In case of severe complications, functional regeneration is delayed, in contrast to volume increase.

Keywords: Hepatobiliary scintigraphy (HBS); liver resection; liver regeneration; posthepatectomy liver failure; liver function test

Submitted Dec 31, 2020. Accepted for publication Mar 03, 2021.

doi: $10.21037 /$ hbsn-20-866

View this article at: http://dx.doi.org/10.21037/hbsn-20-866 


\section{Introduction}

Posthepatectomy liver failure (PHLF) is a potentially lethal complication after major liver resection with an incidence around $7 \%$ in patients with healthy parenchyma and up to $30 \%$ in patients with liver cirrhosis $(1,2)$. The current management is mostly supportive with a high mortality rate while PHLF is considered as the main cause of death after liver resection (3).

After hepatectomy, the remaining hepatocytes have to maintain liver function and at the same time undergo regeneration in order to restore the loss of liver mass. When this is out of balance, the risk of PHLF increases dramatically. PHLF is characterized, according to the criteria set by the International Study Group of Liver Surgery (ISGLS), by the impaired ability of the liver to maintain its function after the fifth postoperative day (4).

In order to minimize the risk of PHLF, pre-operative assessment of the remnant liver is essential. This assessment is traditionally performed using CT-volumetry, calculating the percentage of volume of the future remnant liver (FRL). However, liver function does not always correlate with liver volume and therefore, functional assessment is considered to be more reliable than volume alone in patients evaluated for major liver resection $(5,6)$. Technecium-99m $\left({ }^{99 m} \mathrm{Tc}\right)$ mebrofenin hepatobiliary scintigraphy (HBS) is a quantitative functional test used to estimate global and segmental liver function as now routinely applied in several centers worldwide (7-9).

Additionally, liver stiffness measurements (LSM) are widely used in non-invasive assessment of liver fibrosis and are considered a safe alternative to liver biopsy (10). Besides fibrosis, liver stiffness is also influenced by factors like acute or chronic structural changes. It has been shown to correlate with parenchymal inflammation, bile outflow obstruction and complications related to portal hypertension and hepatic venous pressure gradient disorders (11-15). A recent study showed that LSM can be used to predict PHLF (16).

So far, no studies have been conducted that assess the postoperative changes in measured liver function or elasticity in relation to liver regeneration. Furthermore, there is a lack of data regarding the normal variation of liver function within a single patient; this information is crucial for patients undergoing serial HBS. Lastly, the role of LSM in the perioperative care of patients undergoing liver surgery has not been explored. The aim of this study was to evaluate the early postoperative changes in remnant liver function, volume and elasticity after major liver resection and its correlation with postoperative outcomes. This information can provide new insights that influence selection of candidates for liver resection, their postoperative monitoring and their management. We present the following article in accordance with the STROBE reporting checklist (available at https://hbsn. amegroups.com/article/view/10.21037/hbsn-20-866/rc).

\section{Methods}

\section{Patients}

All patients, aged 18 years or older, scheduled for major liver resection (resection of 3 or more Couinaud segments) were asked to participate in this single-center, prospective observational study.

Patients with bilirubin $>50 \mu \mathrm{mol} / \mathrm{L}$ were not eligible for inclusion in the study since cholestasis impairs liver function testing using HBS due to competitive uptake between bilirubin and mebrofenin (17). These patients, all with perihilar tumors, only were included after successful preoperative biliary drainage. Furthermore, patients undergoing two-stage hepatectomy or Associating Liver Partition and Portal vein Ligation for Staged hepatectomy (ALPPS) in which regeneration takes places in two steps were also excluded in order to obtain a homogenous patient population. Other exclusion criteria were allergy to mebrofenin and pregnancy.

The study was conducted in accordance with the Declaration of Helsinki (as revised in 2013). It was approved by the ethical review board of the Amsterdam University Medical Centers and registered under ID (No. NL63868.018.17). Informed consent was obtained from all individual participants included in the study. Patients were included between February and November 2018.

\section{HBS and CT-volumetry}

According to standard practice in our institution, all patients considered for major liver resection undergo preoperative HBS. This was repeated on the preoperative day of admission in order to examine the variation of liver function per patient and to determine the baseline value for further postoperative, measurements. HBS was repeated on postoperative day 5 to assess early regeneration and 4-6 weeks postoperatively during follow-up for assessment of the late functional recovery. HBS was acquired and processed as described previously (9).

Total liver function (TLF) is represented by the mebrofenin uptake rate (MUR; \%/min). On the dynamic 
acquisitions, regions of interest (ROI) were drawn around the left ventricle (representing the blood pool), liver and total field of view. From these ROI's, three time-activity curves were generated. MUR was calculated based on these parameters according to the formula described by Ekman et al. (18).

For preoperative HBS, the FRL were delineated on the SPECT datasets. Contrast-enhanced diagnostic CT-scans were assessed to assist in anatomical information using the same landmarks as for the volumetric studies. The ratio between the radioactivity counts on the FRL and the total liver represented the functional share of the FRL. This was the percentage of function attributed by the FRL and was multiplied with the TLF to calculate the FRL function.

Data on liver volume were obtained from the concomitant CT images obtained during HBS. The (future) remnant liver was outlined on an axial scan in a semiautomated fashion with manual adjustment to ensure that all extra-hepatic structures and tumors were excluded.

\section{$L S M$}

At the same time points as the HBS, patients underwent transient elastography (TE) for the assessment of liver stiffness. TE was performed with the Fibroscan ${ }^{\circledR}$ (Echosens, Paris, France) using the M- or XL-probe. The probe was positioned in the right midaxillary line, between the ninth to eleventh intercostal space for patients undergoing left sided resection, or just beneath the xyphoid for patients undergoing right sided resection. It was repeated at the same location for postoperative assessment (19).

A low-frequency shear wave $(50 \mathrm{~Hz})$, generated by a mechanical push, travels through the hepatic tissue where the velocity of wave propagation is measured. The wave velocity is proportional to tissue stiffness which is expressed in kilopascal $(\mathrm{kPa})$.

The assessment was considered successful when at least 10 measurements were performed at the same location, the success rate was higher than $80 \%$ and when the interquartile range (IQR) did not exceed $30 \%$ of the median (20).

\section{Outcomes}

The primary outcome parameters were the changes in liver function and liver stiffness between baseline, postoperative day 5 and 4-6 weeks postoperatively in \%/min.

Secondary outcomes were the correlation of the changes in liver function with baseline liver volume, morbidity and 90-day mortality. Severe postoperative morbidity was defined as any complication of Clavien-Dindo grade IIIa or higher within 30 days of surgery (21). PHLF was defined and graded according to ISGLS criteria. PHLF grade B or C were considered clinically relevant (22).

\section{Statistical analysis}

Continuous data are expressed as median and IQR. Discrete variables are expressed as absolute numbers and relative frequencies. Differences in non-parametric data were tested using the Wilcoxon signed rank test for paired data or the Mann-Whitney $\mathrm{U}$ test for unpaired data. A two-sided $\mathrm{P}$ value less than 0.05 was considered statistically significant. Statistical analysis was carried out using IBM SPSS Statistics (version 24.0; IBM Corp., New York, USA).

\section{Results}

In total, 24 patients were included in this study. Six were found unresectable during laparotomy due to peritoneal metastasis $(n=3)$, progression of liver metastases $(n=2)$ or involvement of both portal vein and hepatic artery $(\mathrm{n}=1)$. The remaining 18 underwent major liver resection. Patients' characteristics are presented in Table 1.

\section{Postoperative outcomes}

Ten patients (56\%) had severe postoperative complications $(\mathrm{CD} \geq 3 \mathrm{~A})$ that occurred during the first five postoperative days. These were bile leakage in four patients, septic complications in three patients, ascites requiring drainage in one patient, partial ischemia of the FRL in one patient. One patient developed PHLF and eventually died on postoperative day 11 .

\section{Preoperative assessment of the FRL}

A total of 20 patients underwent HBS both preoperatively and at day of admission. Four patients did not undergo additional HBS on the day of admission because preoperative HBS was performed within the same week as the surgery.

The median time between preoperative HBS and HBS at day of admission was 18 [10-26] days. There were no differences in TLF [median 13.8 (12.0-16.2) vs. 15.4 (12.6-16.4) \%/min, $\mathrm{P}=0.601$ ) or FRL function [median 3.1 $(2.7-5.3)$ vs. $\left.3.6(2.9-5.2) \% / \mathrm{min} / \mathrm{m}^{2}, \mathrm{P}=0.263\right]$ between 
Table 1 Patient characteristics $(\mathrm{n}=18)$

\begin{tabular}{|c|c|}
\hline Characteristics & Value \\
\hline Age (years) & $63[53-71]$ \\
\hline Male, $\mathrm{n}(\%)$ & $9(50.0)$ \\
\hline BMI $\left(\mathrm{kg} / \mathrm{m}^{2}\right)$ & $25.0[21.6-28.3]$ \\
\hline $\mathrm{BSA}\left(\mathrm{m}^{2}\right)$ & $1.88[1.72-1.99]$ \\
\hline \multicolumn{2}{|c|}{ ASA physical status classification, $\mathrm{n}(\%)$} \\
\hline 1 & $3(17.0)$ \\
\hline 2 & $7(39.0)$ \\
\hline 3 & $8(44.0)$ \\
\hline \multicolumn{2}{|l|}{ Procedure, n (\%) } \\
\hline Right hemihepatectomy & $8(44.0)$ \\
\hline Extended right hemihepatectomy & $5(28.0)$ \\
\hline Left hemihepatectomy & $3(17.0)$ \\
\hline Segmentectomy $\geq 3$ & $2(12.0)$ \\
\hline \multicolumn{2}{|l|}{ Indication, n (\%) } \\
\hline Colorectal liver metastasis & $4(21.0)$ \\
\hline Hepatocellular carcinoma & $1(6.0)$ \\
\hline Cholangiocarcinoma & $11(61.0)$ \\
\hline Gall bladder carcinoma & $1(6.0)$ \\
\hline Neuro-endocrine tumor & $1(6.0)$ \\
\hline Open, n (\%) & $17(94.0)$ \\
\hline Laparoscopic, n (\%) & $1(6.0)$ \\
\hline Pre-op TLV (mL) & $1,874[1,289-2,382]$ \\
\hline Pre-op FRLV (\%) & $37.2[32.5-53.2]$ \\
\hline Pre-op TLF (\%/min) & $14.3[13.4-16.4]$ \\
\hline Pre-op FRLF (\%/min) & 5.96 [4.69-8.35] \\
\hline
\end{tabular}

Continuous data are expressed as median and IQR. TLV, total liver volume; FRLV, future remnant liver volume; TLF, total liver function; FRLF, future remnant liver function; IQR, interquartile range.

preoperative HBS and HBS at day of admission (Figure 1).

At preoperative HBS, the median bilirubin value was [18 (10-31) $\mu \mathrm{mol} / \mathrm{L} ; 1.05(0.58-1.81) \mathrm{mg} / \mathrm{dL}]$ which did differ from the bilirubin level at day of admission [12 (8-20) $\mu \mathrm{mol} / \mathrm{L} ; 0.7(0.46-1.17) \mathrm{mg} / \mathrm{dL}]$.

Likewise, there were no differences in total liver volume (TLV) [1,920 (1,316-2,341) vs. 1,802 (1,439-2,252) mL, $\mathrm{P}=0.394]$ and $\mathrm{FRL}$ volume share $[41 \%(33-56 \%)$ vs. $47 \%$

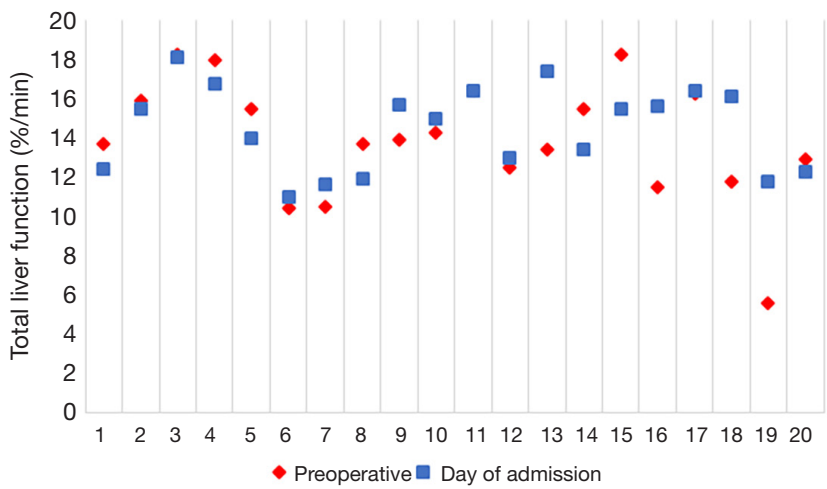

Figure 1 Sequential HBS total liver function in 20 patients. HBS, hepatobiliary scintigraphy.

(33-62\%), $\mathrm{P}=0.730$ ] between preoperative HBS and HBS at day of admission.

\section{Functional and volumetric regeneration}

Between baseline and postoperative day 5, overall, there was a significant increase of (future) remnant liver function, from a median value of $6.9(5.4-10.9)$ to $9.6(6.7-13.8) \% / \mathrm{min} / \mathrm{m}^{2}$, $\mathrm{P}=0.004$. Remnant liver function did not further increase significantly between postoperative day 5 to postoperative 4-6 weeks with a median of $9.6(6.7-13.8)$ to $10.9(8.8-13.6)$ $\% / \mathrm{min} / \mathrm{m}^{2}, \mathrm{P}=0.177$. These changes are also shown in Figure 2.

Similarly, there was a significant increase in remnant liver volume between baseline and postoperative day 5 , from a median of $795.5(538.3-1,037.5)$ to $1,080.0$ (854.0 $1,283.3) \mathrm{mL}, \mathrm{P}<0.001$. However, in contrast to function, remnant liver volume continued to increase significantly from postoperative day 5 to postoperative 4-6 weeks with median values of $1,080.0(854.0-1,283.3)$ and $1,222.0$ $(1,016.0-1,380.5) \mathrm{mL}$, respectively, $\mathrm{P}=0.035$. See also Figure 2.

When comparing patients with and without severe postoperative complications that had occurred during the first 5 postoperative days, a difference was found in the dynamics of parenchymal regeneration. Patients with severe postoperative complications $(\mathrm{CD} \geq 3 \mathrm{~A})$ showed no significant increase in FRL function between baseline and postoperative day $5(\mathrm{P}=0.203)$, whereas patients without severe postoperative complications, showed significant functional increase $(\mathrm{P}=0.012)$. Eventually after $4-6$ weeks, both groups showed a significant increase in median remnant liver function compared to baseline $(\mathrm{P}=0.012$ and $\mathrm{P}=0.038)$. 

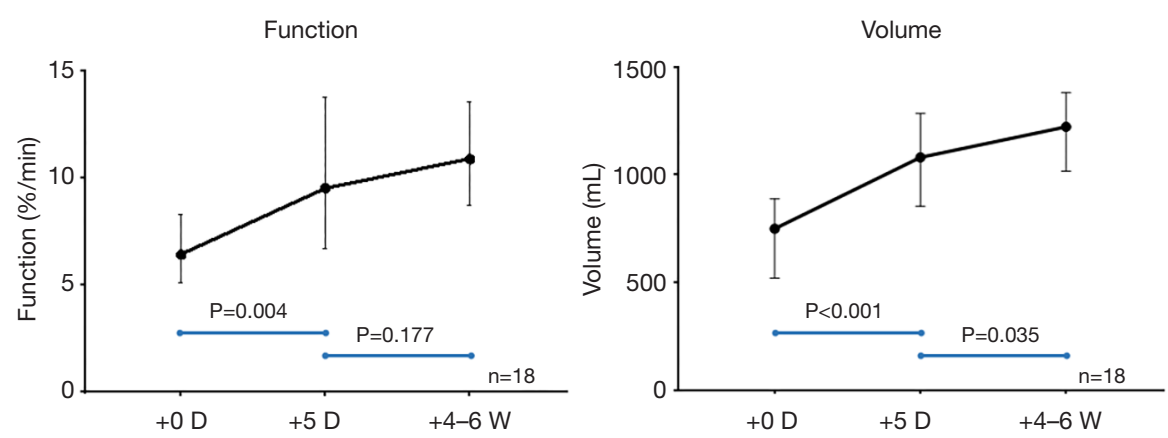

Figure 2 Change in remnant liver function $(\% / \mathrm{min})$ and volume $(\mathrm{mL})$.
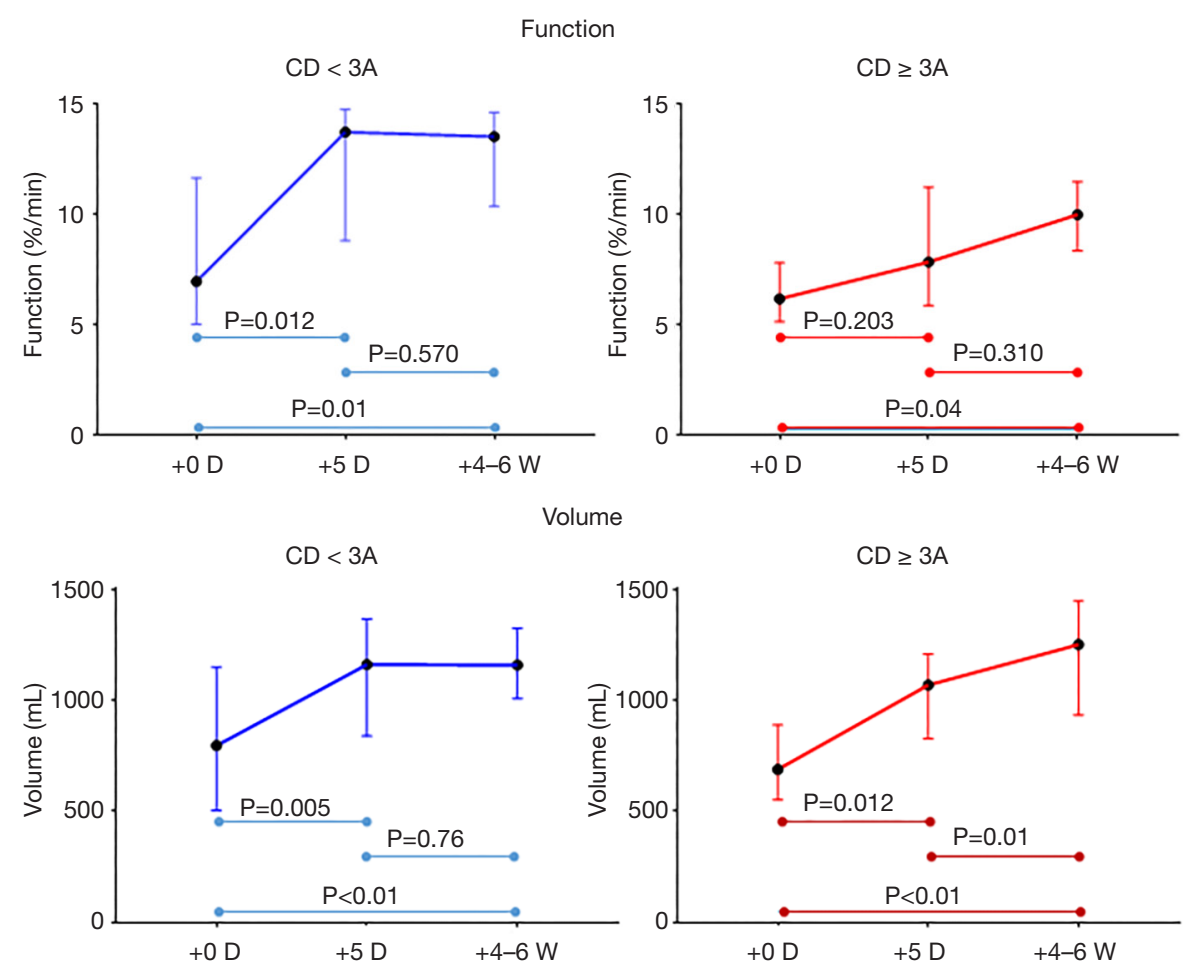

Figure 3 Change in remnant liver function $(\% / \mathrm{min})$ and volume $(\mathrm{mL})$ in patients with and without severe postoperative complications.

This data suggests that patients with early postoperative complications had delayed functional regeneration (Figure 3).

This was however not the case for liver volume, which had increased significantly at postoperative day 5 in both patients with $(\mathrm{P}=0.012)$ and without $(\mathrm{P}=0.005)$ severe postoperative complications (Figures 3 and 4 ).

\section{Change in liver stiffness}

At baseline, liver elasticity did not differ between the different groups of included pathologies, $\mathrm{P}=0.540$. Between baseline and the first 5 postoperative days, there was a significant increase in liver elasticity of the FRL [from 10.8 (5.7-18.7) to $17.5(12.4-22.6) \mathrm{kPa}, \mathrm{P}=0.018]$. This gradually recovered after 4-6 weeks to a median of $10.9(5.7-18.8) \mathrm{kPa}$ (T3 vs. $\mathrm{T} 4, \mathrm{P}=0.079$ ) (Figure 5).

In regard with severe postoperative complications, there were no significant differences in liver elasticity at baseline between patients with and without $\mathrm{CD} \geq 3 \mathrm{~A}$ complications [11.1 (5.99-14.8) vs. 8.9 (5.6-19.4) kPa; $\mathrm{P}=0.770]$. Patients 

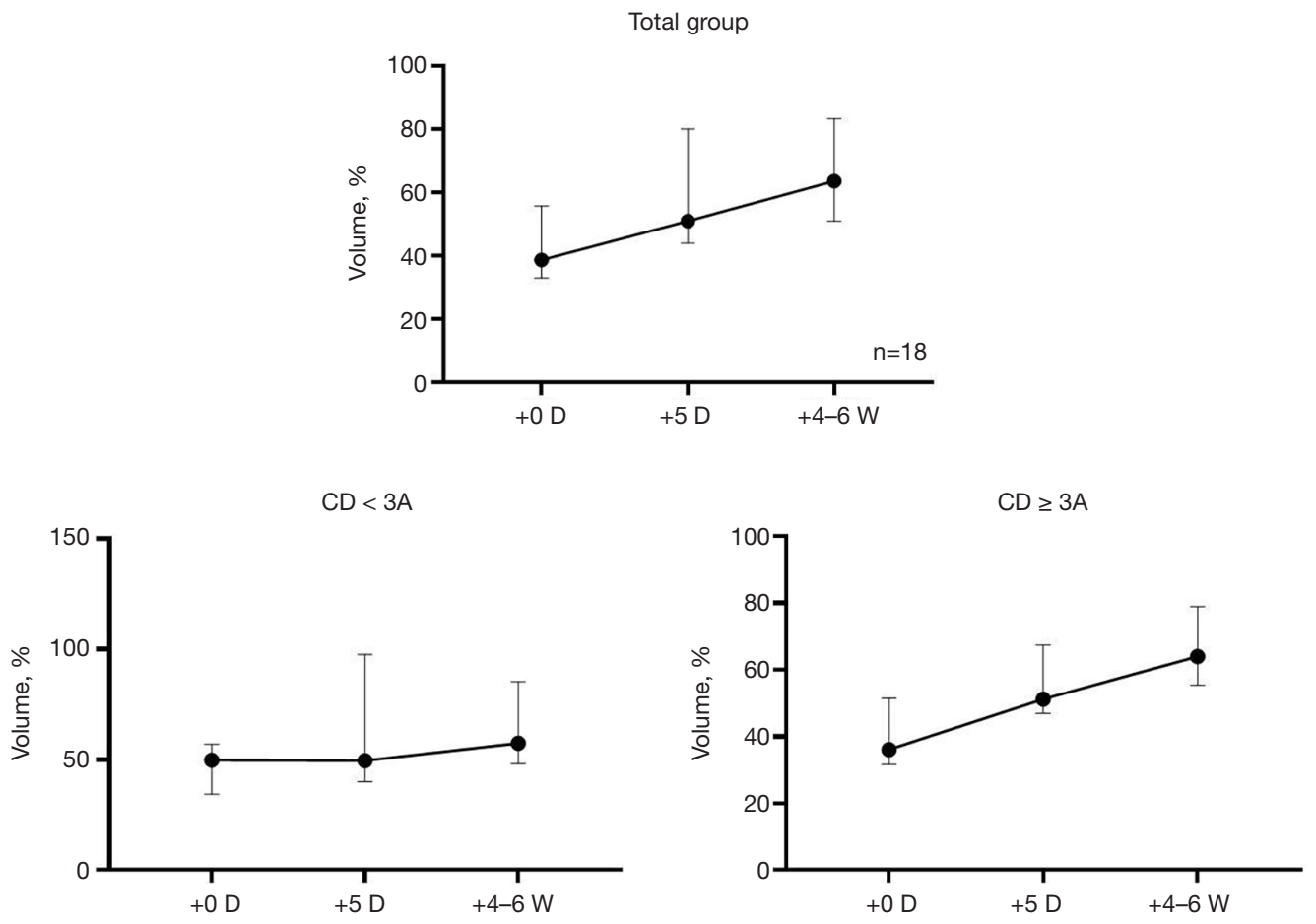

Figure 4 Change in volume (\%) in all patients and in patients with and without severe postoperative complications.

with $\mathrm{CD} \geq 3 \mathrm{~A}$ however, showed a tendency to a larger increase in liver elasticity 5 days after resection, compared to patients with no complications or less than $\mathrm{CD} \geq 3 \mathrm{~A}$ [2.6 (0-15.6) $\mathrm{kPa}, \mathrm{P}=0.176, \mathrm{n}=7$ vs. $4.5(0.1-13.5) \mathrm{kPa}$, $\mathrm{P}=0.066, \mathrm{n}=10 ;$ Figure 5$]$.

\section{Discussion}

Regeneration of the remnant liver occurs predominantly during the first 5 days after resection, rendering this period as crucial for the development of PHLF. In case of severe complications during the first 5 postoperative days, functional regeneration was delayed. This was not noted for volume increase. Uncompromised regeneration in the first 5 days after resection seems crucial to prevent PHLF. So far, this is the first study monitoring postoperative liver function using quantitative liver function tests before and after resection.

These results further emphasize the importance of the early postoperative course in the development of PHLF. Day 5 was chosen because in a large cohort of patients who underwent liver resection without postoperative complications, biochemical blood tests, reflecting liver function, returned to normal values on day 5 , corresponding with the normalization of liver function at day 5 (23). This analogy is also found for the ' $50 / 50$ criteria' where PHLF is defined as a combination of prothrombin time (PT) $<50 \%$ and serum bilirubin $>50 \mu \mathrm{mol} / \mathrm{L}$ on postoperative day 5 , as well as for the ISGLS criteria $(22,24)$.

PHLF has a multifactorial etiology and occurs as a result of a decrease in hepatocellular mass in combination with patient, surgical and postoperative factors. The most common postoperative risk factors include complications such as bile leakage and septic complications, ultimately leading to a 'second-hit' on top of the residual capacity of the remnant liver. This combination impedes regeneration of the remnant liver and greatly enhances the risk of hepatic insufficiency. The data in this study confirm that in case of postoperative complications, there is a delay in hepatic functional regeneration further contributing to vulnerability of the liver remnant.

Inflammation is an important trigger in the initiation and augmentation of liver regeneration, however, in cases of severe, systemic inflammation such as in sepsis, the balance is shifted towards a detrimental effect, leading to hepatocellular injury, liver dysfunction and impaired regeneration (25). Furthermore, in case of bile leakage, disruption of the enterohepatic bile-gut axis leading to a 


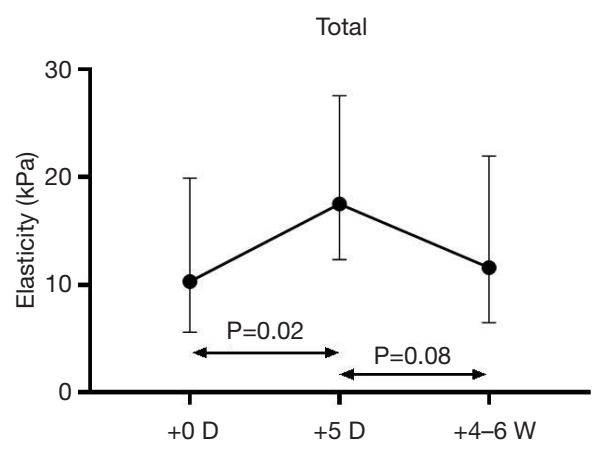

$\mathrm{CD}<3 \mathrm{~A}$

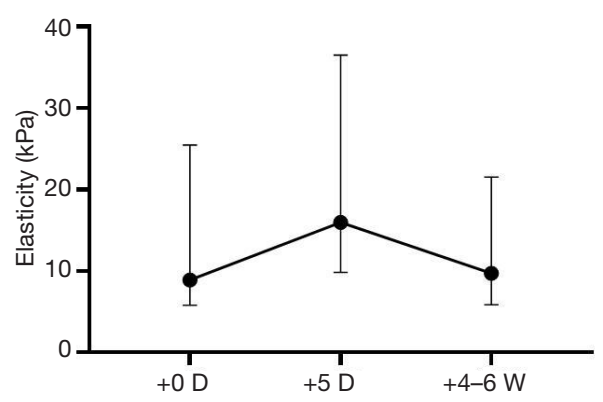

$C D \geq 3 A$

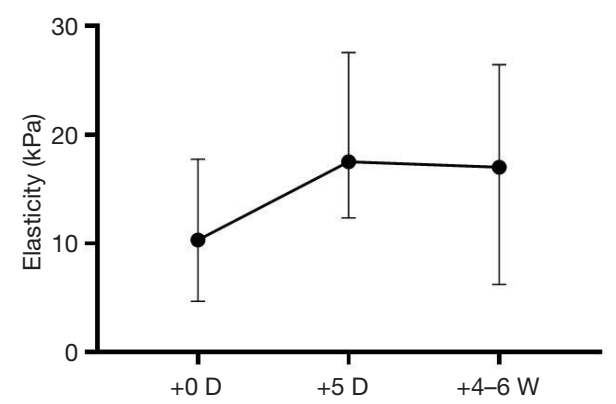

Figure 5 Change in liver elasticity $(\mathrm{kPa})$ in all patients and in patients with and without severe postoperative complications.

loss of bile acids also contributes to PHLF. Bile acids are considered hepatotoxic in high concentration, however, they trigger hepatocyte proliferation through activation of several nuclear receptors (26,27). Early detection and management of bile leakage might therefore help to prevent PHLF.

Sequential HBS at different time points did not show differences in TLF. In one patient, the difference between the two sequential HBS studies was remarkably high: $6.2 \% / \mathrm{min}(5.8$ vs. $11.6 \% / \mathrm{min})$. This is explained by hyperbilirubinemia occurring during the first scan, with a serum bilirubin of $69 \mu \mathrm{mol} / \mathrm{L}$. The patient underwent biliary drainage resulting in a reduction of bilirubin to $40 \mu \mathrm{mol} / \mathrm{L}$ during the second scan. All other patients had bilirubin levels below $30 \mu \mathrm{mol} / \mathrm{L}$ and did not show significant differences in TLF between the scans. As reported earlier, increased plasma bilirubin affects the hepatic uptake of mebrofenin due to competitive uptake (28). It is therefore important that the use of HBS in the presence of obstructive cholestasis is restricted to patients having undergone adequate biliary drainage (29).

The discrepancy between function and volume is applicable to the regenerative response after major liver resection. As reported earlier, volume increase does not necessarily correlate with functional increase. This is especially the case in patients that have undergone liver augmenting techniques such as portal vein embolization or ALPPS $(6,30)$. The findings reported in the latter setting corroborate the results of the present study, showing that functional liver regeneration was faster than recovery of liver volume.

Liver elasticity increased in the first 5 postoperative days after resection in this series. The increase was greater in patients with severe postoperative complications compared to patients with an uncomplicated course. Acute changes in parenchymal elasticity occur because of a variety of reasons, including hemodynamic changes, inflammation or acute cellular rejection $(31,32)$. Preliminary studies carried out in liver transplant patients showed that changes in liver stiffness might be predictive of postoperative outcomes. LSM in the early post-transplant period showed that patients with major complications had significantly higher increase in stiffness than those without complications (32). Another study showed that stiffness values in smaller remnant livers increased more than in larger remnant livers (33). Therefore, the change of remnant liver stiffness might reflect the efficiency of liver regeneration and potentially predicts liver failure. Furthermore, parenchymal edema 
could also influence liver stiffness, and also have a role in the development of PHLF with increased portal pressure and ascites. Until now, LSM has not been applied for monitoring patients after liver resection or for diagnosing acute liver pathologies. More prospective studies are needed to evaluate the application of LSM in this setting as a quick and non-invasive bedside method to assess patients at risk of PHLF.

This study has several limitations, including the small sample size and the heterogeneous patient population. Furthermore, there is a heterogeneity in the extent of the resections performed and therefore, in the remnant liver function and volume fractions recorded. Even though the first severe complications occurred during the first five postoperative days, it is yet uncertain how complications occurring in a later stage affect subsequent liver regeneration.

In conclusion, this study demonstrated that functional liver regeneration predominantly occurred in the first 5 days after resection while the increase in liver volume progressed for 4-6 weeks. Postoperative complications significantly delayed the recovery of liver function, increasing the risk of (remnant) liver failure.

\section{Acknowledgments}

Funding: None.

\section{Footnote}

Reporting Checklist: The authors have completed the STROBE reporting checklist. Available at https://hbsn. amegroups.com/article/view/10.21037/hbsn-20-866/rc

Data Sharing Statement: Available at https://hbsn. amegroups.com/article/view/10.21037/hbsn-20-866/dss

Conflicts of Interest: All authors have completed the ICMJE uniform disclosure form (available at https://hbsn. amegroups.com/article/view/10.21037/hbsn-20-866/coif). TMvG serves as an unpaid Deputy Editor-in-Chief of Hepatobiliary Surgery and Nutrition. The other authors have no conflicts of interest to declare.

Ethical Statement: The authors are accountable for all aspects of the work in ensuring that questions related to the accuracy or integrity of any part of the work are appropriately investigated and resolved. The study was conducted in accordance with the Declaration of Helsinki (as revised in 2013). The study was approved by institutional ethics board of Amsterdam University Medical Centers (No. NL63868.018.17) and informed consent was taken from all individual participants.

Open Access Statement: This is an Open Access article distributed in accordance with the Creative Commons Attribution-NonCommercial-NoDerivs 4.0 International License (CC BY-NC-ND 4.0), which permits the noncommercial replication and distribution of the article with the strict proviso that no changes or edits are made and the original work is properly cited (including links to both the formal publication through the relevant DOI and the license). See: https://creativecommons.org/licenses/by-nc-nd/4.0/.

\section{References}

1. van den Broek MA, Olde Damink SW, Dejong CH, et al. Liver failure after partial hepatic resection: definition, pathophysiology, risk factors and treatment. Liver Int 2008;28:767-80.

2. Golse N, Bucur PO, Adam R, et al. New paradigms in post-hepatectomy liver failure. J Gastrointest Surg 2013;17:593-605.

3. van Mierlo KM, Schaap FG, Dejong CH, et al. Liver resection for cancer: New developments in prediction, prevention and management of postresectional liver failure. J Hepatol 2016;65:1217-31.

4. Lafaro K, Buettner S, Maqsood H, et al. Defining Post Hepatectomy Liver Insufficiency: Where do We stand? J Gastrointest Surg 2015;19:2079-92.

5. de Graaf W, van Lienden KP, van den Esschert JW, et al. Increase in future remnant liver function after preoperative portal vein embolization. Br J Surg 2011;98:825-34.

6. Rassam F, Olthof PB, van Lienden KP, et al. Functional and volumetric assessment of liver segments after portal vein embolization: Differences in hypertrophy response. Surgery 2019;165:686-95.

7. Bennink RJ, Dinant S, Erdogan D, et al. Preoperative assessment of postoperative remnant liver function using hepatobiliary scintigraphy. J Nucl Med 2004;45:965-71.

8. Cieslak KP, Bennink RJ, de Graaf W, et al. Measurement of liver function using hepatobiliary scintigraphy improves risk assessment in patients undergoing major liver resection. HPB (Oxford) 2016;18:773-80.

9. Rassam F, Olthof PB, Richardson H, et al. Practical guidelines for the use of technetium-99m mebrofenin 
hepatobiliary scintigraphy in the quantitative assessment of liver function. Nucl Med Commun 2019;40:297-307.

10. Friedrich-Rust M, Ong MF, Martens S, et al. Performance of transient elastography for the staging of liver fibrosis: a meta-analysis. Gastroenterology 2008;134:960-74.

11. Bureau C, Metivier S, Peron JM, et al. Transient elastography accurately predicts presence of significant portal hypertension in patients with chronic liver disease. Aliment Pharmacol Ther 2008;27:1261-8.

12. Choi SY, Jeong WK, Kim Y, et al. Shear-wave elastography: a noninvasive tool for monitoring changing hepatic venous pressure gradients in patients with cirrhosis. Radiology 2014;273:917-26.

13. Boleslawski E, Petrovai G, Truant S, et al. Hepatic venous pressure gradient in the assessment of portal hypertension before liver resection in patients with cirrhosis. Br J Surg 2012;99:855-63.

14. Castéra L, Vergniol J, Foucher J, et al. Prospective comparison of transient elastography, Fibrotest, APRI, and liver biopsy for the assessment of fibrosis in chronic hepatitis C. Gastroenterology 2005;128:343-50.

15. Corpechot C, El Naggar A, Poujol-Robert A, et al. Assessment of biliary fibrosis by transient elastography in patients with PBC and PSC. Hepatology 2006;43:1118-24.

16. Rajakannu M, Cherqui D, Ciacio O, et al. Liver stiffness measurement by transient elastography predicts late posthepatectomy outcomes in patients undergoing resection for hepatocellular carcinoma. Surgery 2017;162:766-74.

17. de Graaf W, Hausler S, Heger M, et al. Transporters involved in the hepatic uptake of $(99 \mathrm{~m}) \mathrm{Tc}-$ mebrofenin and indocyanine green. J Hepatol 2011;54:738-45.

18. Ekman M, Fjalling M, Friman S, et al. Liver uptake function measured by IODIDA clearance rate in liver transplant patients and healthy volunteers. Nucl Med Commun 1996;17:235-42.

19. Sandrin L, Fourquet B, Hasquenoph JM, et al. Transient elastography: a new noninvasive method for assessment of hepatic fibrosis. Ultrasound Med Biol 2003;29:1705-13.

20. Foucher J, Chanteloup E, Vergniol J, et al. Diagnosis of cirrhosis by transient elastography (FibroScan): a prospective study. Gut 2006;55:403-8.

21. Dindo D, Demartines N, Clavien PA. Classification of surgical complications: a new proposal with evaluation in a cohort of 6336 patients and results of a survey. Ann Surg 2004;240:205-13.

22. Rahbari NN, Garden OJ, Padbury R, et al. Posthepatectomy liver failure: a definition and grading by the International Study Group of Liver Surgery (ISGLS).
Surgery 2011;149:713-24.

23. Reissfelder C, Rahbari NN, Koch M, et al. Postoperative course and clinical significance of biochemical blood tests following hepatic resection. Br J Surg 2011;98:836-44.

24. Balzan S, Belghiti J, Farges O, et al. The "50-50 criteria" on postoperative day 5: an accurate predictor of liver failure and death after hepatectomy. Ann Surg 2005;242:824-8, discussion 8-9.

25. Taub R. Liver regeneration: from myth to mechanism. Nat Rev Mol Cell Biol 2004;5:836-47.

26. Otao R, Beppu T, Isiko T, et al. External biliary drainage and liver regeneration after major hepatectomy. Br J Surg 2012;99:1569-74.

27. de Haan L, van der Lely SJ, Warps AK, et al. Posthepatectomy liver regeneration in the context of bile acid homeostasis and the gut-liver signaling axis. J Clin Transl Res 2018;4:1-46.

28. Okuda H, Nunes R, Vallabhajosula S, et al. Studies of the hepatocellular uptake of the hepatobiliary scintiscanning agent 99mTc-DISIDA. J Hepatol 1986;3:251-9.

29. Olthof PB, Coelen RJS, Bennink RJ, et al. (99m)Tcmebrofenin hepatobiliary scintigraphy predicts liver failure following major liver resection for perihilar cholangiocarcinoma. HPB (Oxford) 2017;19:850-8.

30. Cieslak KP, Olthof PB, van Lienden KP, et al. Assessment of Liver Function Using (99m)Tc-Mebrofenin Hepatobiliary Scintigraphy in ALPPS (Associating Liver Partition and Portal Vein Ligation for Staged Hepatectomy). Case Rep Gastroenterol 2015;9:353-60.

31. Sagir A, Erhardt A, Schmitt M, et al. Transient elastography is unreliable for detection of cirrhosis in patients with acute liver damage. Hepatology 2008;47:592-5.

32. Inoue $Y$, Sugawara $Y$, Tamura S, et al. Validity and feasibility of transient elastography for the transplanted liver in the peritransplantation period. Transplantation 2009;88:103-9.

33. Ninomiya $M$, Shirabe K, Ijichi H, et al. Temporal changes in the stiffness of the remnant liver and spleen after donor hepatectomy as assessed by acoustic radiation force impulse: A preliminary study. Hepatol Res 2011;41:579-86.

Cite this article as: Rassam F, Olthof PB, Takkenberg B, Besselink MG, Busch OR, Erdmann JI, Swijnenburg RJ, van Lienden KP, Beuers UH, Bennink RJ, van Gulik TM. Functional assessment of liver regeneration after major hepatectomy. HepatoBiliary Surg Nutr 2022;11(4):530-538. doi: $10.21037 / \mathrm{hbsn}-20-866$ 